\title{
Optimal maintenance and consolidation therapy for multiple myeloma in actual clinical practice
}

\author{
Ho Sup Lee ${ }^{1}$ and Chang-Ki Min ${ }^{2}$
}

\begin{abstract}
${ }^{1}$ Department of Internal Medicine, Kosin University College of Medicine, Busan; ${ }^{2}$ Division of Hematology, Department of Internal Medicine, College of Medicine, Seoul St. Mary's Hospital, The Catholic University of Korea, Seoul, Korea
\end{abstract}

Received: April 2, 2016

Accepted: August 23, 2016

\section{Correspondence to}

Chang-Ki Min, M.D.

Division of Hematology,

Department of Internal

Medicine, College of Medicine,

Seoul St. Mary's Hospital,

The Catholic University of

Korea, 222 Banpo-daero,

Seocho-gu, Seoul 06591, Korea

Tel: $+82-2-2258-6053$

Fax: +82-2-599-3589

E-mail: ckmin@catholic.ac.kr
Multiple myeloma is an incurable malignant plasma cell-originating cancer. Although its treatment outcomes have improved with the use of glucocorticoids, alkylating drugs, and novel agents, including proteasome inhibitors (bortezomib and carfilzomib) and immunomodulatory drugs (thalidomide, lenalidomide, and pomalidomide), relapse remains a serious problem. Strategies to improve outcomes following autologous stem cell transplantation and frontline treatments in non-transplant patients include consolidation to intensify therapy and improve the depth of response and maintenance therapy to achieve long-term disease control. Many clinical trials have reported increased progression-free and overall survival rates after consolidation and maintenance therapy. The role of consolidation/maintenance therapy has been assessed in patients eligible and ineligible for transplantation and is a valuable option in clinical trial settings. However, the decision to use consolidation and/or maintenance therapy needs to be guided by the individual patient situation in actual clinical practice. This review analyzes the currently available evidence from several reported clinical trials to determine the optimal consolidation and maintenance therapy in clinical practice.

Keywords: Multiple myeloma; Maintenance; Consolidation; Proteasome inhibitors; Immunologic factors

\section{INTRODUCTION}

Multiple myeloma (MM) is a plasma-cell neoplasm characterized by skeletal destruction, renal failure, anemia, hypercalcemia, and other systemic symptoms, including disrupted heart function [1-4]. In the past, the combination of melphalan and prednisone was the standard treatment for MM. However, improved survival has more recently been achieved by incorporating novel agents [1]. In 1996, Attal et al. [5] demonstrated the clinical significance of autologous stem cell transplantation (ASCT) as a consolidation therapy in eligible patients. They reported that a high-dose therapy combined with stem-cell support improves the response rate, event-free survival (EFS), and overall survival (OS).
Seven years later, Attal et al. [6] confirmed the clinical impact of consolidation therapy using tandem ASCT in patients with MM. Compared with a single ASCT, double transplantation improves OS in patients with newly diagnosed MM, suggesting a beneficial role of consolidation therapy. Novel agents, such as immunomodulatory derivatives (IMiDs) and proteasome inhibitors (PIs), have been incorporated into induction therapies, which has resulted in unprecedented rates of complete response (CR) that rival those previously seen with conventional chemotherapy and subsequent ASCT $[7,8]$. Moreover, an improvement in the depth of response has been observed following consolidation therapy with novel agents. Usmani et al. [9] attempted total therapy (TT), including induction, transplant, consolidation, and maintenance therapy, in patients with 
MM and presented the long-term outcomes. Based on Cox model-adjusted statistics, OS, progression-free survival (PFS), and CR duration all improved with transitions from TT1 to TT2 and TT3; improvement was also evident from time-to-progression estimates, 4-year conditional survival data, and cumulative relative survival.

The excellent activity shown by IMiDs and/or PIs before ASCT has led to their investigational use as consolidation and maintenance therapy after ASCT [10-12]. Consolidation therapy is defined as a distinct course of therapy aimed at increasing the depth of response. It consists of a limited number of cycles of a single agent or combination therapy or a second transplant step. Maintenance therapy is then applied for a prolonged period $\geq 12$ months and typically for at least 2 to 3 years and even until progression. The overall aim of this therapy is to maintain the depth of response achieved in previous treatments by applying novel treatments usually at a lower dose than that used during either induction or consolidation. The current strategies for treating patients with transplant-eligible MM include induction, ASCT, and consolidation and maintenance therapy, whereas those for transplant-ineligible patients include induction and consolidation and maintenance therapy. However, cost-effectiveness, compliance, toxicities, and quality of life (QoL) must be considered in actual clinical practice, in addition to improvements in survival and response during maintenance therapy. This review focuses on maintenance and consolidation therapy, offering an overview of the different strategies available for patients with MM who are treated in a clinical trial setting as well as in actual clinical practice.

\section{CONSOLIDATION THERAPY IN PATIENTS ELIGIBLE FOR TRANSPLANTATION}

Consolidation therapy generally has a short duration and aims to increase the frequency and depth of response obtained with previous treatments, including high-dose melphalan and ASCT [13]. Novel agents, such as thalidomide, lenalidomide, and bortezomib, have been successfully combined with cytotoxic drugs and have been widely investigated as induction therapy prior to ASCT [14-18]. The combinations of thalidomide-dexamethasone (TD), bortezomib plus dexamethasone (VD), and doxorubicin or cyclophosphamide with TD have been assessed in terms of increased overall response rate, including CR. However, increasing the depth of response to the level of undetectable minimal residual disease (MRD) and maintaining a sustained CR are stronger predictors of a favorable long-term outcome than attainment of CR [19,20]. The impact of consolidation therapy on clinical outcomes for transplant-eligible patients with MM is discussed below and summarized in Table $1[8,21-25]$. Patients in the Gruppo Italiano Malattie EMatologiche dell'Adulto trial were randomized to receive either TD or bortezomib, thalidomide plus dexamethasone (VTD) induction therapy, followed by double ASCT and two consolidation cycles of assigned chemotherapy [8]. After induction, CR/near complete response (nCR) rates were similar in the VTD (63.1\%) and TD (54.7\%) groups. After consolidation, the $\mathrm{CR} / \mathrm{nCR}$ (73.1\% vs. 60.9\%) rate was significantly higher in VTD-treated patients. Mellqvist et al. [21] compared consolidation therapy with single-agent bortezomib with no consolidation in a phase 3 trial. The rates of very good partial response (VGPR) and PFS were significantly higher in the bortezomib group than in the consolidation therapy group (71\% vs. $57 \%, p<0.01 ; 27$ months vs. 20 months, $p=0.05$, respectively). Ladetto et al. [22] implemented treatment with VTD in patients who achieved at least VGPR after vincristine/adriamycin/dexamethasone (VAD)/double ASCT; the CR rate increased from 15\% to $49 \%$. Attal et al. [23] presented results of the Intergroupe Francophone du Myelome (IFM) 2005-02 trial. In their study, patients who underwent ASCT received two cycles of lenalidomide monotherapy as consolidation with further randomization to lenalidomide maintenance versus no maintenance. Lenalidomide consolidation resulted in improved responses; CR increased from $14 \%$ to $20 \%(p<$ $0.001)$ and VGPR increased from $58 \%$ to $69 \%(p<0.001)$. In the IFM 2008 study, Roussel et al. [24] assessed the efficacy of two VRD cycles (bortezomib, lenalidomide, and dexamethasone) after previous VRD induction treatment and single ASCT. They found that consolidation increased the VGPR rate by $26 \%$. 
Table 1. Consolidation therapy after autologous stem cell transplantation for newly diagnosed multiple myeloma

\begin{tabular}{|c|c|c|c|c|c|c|}
\hline Study & Type of trial & Treatment scheme & $\begin{array}{c}\text { No. of } \\
\text { patients }\end{array}$ & Response rate & EFS or PFS & OS \\
\hline \multicolumn{7}{|c|}{ Bortezomib-based } \\
\hline $\begin{array}{l}\text { Cavo et al. } \\
(2012)[8]\end{array}$ & Phase III & VTD vs. TD & $\begin{array}{l}160 \text { vs. } \\
161\end{array}$ & $\begin{array}{l}\text { CR/nCR preconsolidation: } \\
63 \% \text { vs. } 55 \%(p=\mathrm{NS}) \\
\text { CR/nCR postconsolidation: } \\
73 \% \text { vs. } 61 \%(p=0.020)\end{array}$ & $\begin{array}{c}\text { 3-yr PFS: } 60 \% \text { vs. } \\
48 \%(p=0.042)\end{array}$ & $\begin{array}{l}\text { 3-yr OS: } 90 \% \text { vs. } \\
88 \%(p=\mathrm{NS})\end{array}$ \\
\hline $\begin{array}{l}\text { Mellqvist et } \\
\text { al. } \\
(2013)[21]\end{array}$ & Phase III & $\begin{array}{l}\text { Bortezomib } \\
\text { consolidation vs. } \\
\text { no consolidation }\end{array}$ & $\begin{array}{c}187 \text { vs. } \\
183\end{array}$ & $\begin{array}{l}\geq \text { VGPR preconsolidation: } \\
40 \% \text { vs. } 39 \%(p=\mathrm{NS}) \\
\geq \text { VGPR postconsolidation: } \\
71 \% \text { vs. } 57 \%(p=0.009)\end{array}$ & $\begin{array}{l}\text { Median PFS: } 27 \\
\text { mon vs. } 20 \text { mon } \\
(p=0.05)\end{array}$ & $\begin{array}{l}3 \text {-yr OS: } 80 \% \text { vs. } \\
80 \%(p=N S)\end{array}$ \\
\hline $\begin{array}{l}\text { Leleu et al. } \\
(2013)[25]\end{array}$ & $\begin{array}{l}\text { Retrospective } \\
\text { comparison }\end{array}$ & $\begin{array}{l}\text { VTD consolidation } \\
\text { vs. no consolidation }\end{array}$ & $\begin{array}{l}121 \text { vs. } \\
96\end{array}$ & $\begin{array}{l}\text { CR postconsolidation: } \\
52 \% \text { vs. } 30 \%(p=0.001)\end{array}$ & $\begin{array}{l}\text { Median TTP: } \\
\text { NR vs. } 25 \text { mon } \\
(p=0.005)\end{array}$ & $\begin{array}{l}4-y r \text { OS: } 84 \% \text { vs. } \\
91 \%(p=N S)\end{array}$ \\
\hline $\begin{array}{l}\text { Ladetto et al. } \\
\text { (2010) [22] }\end{array}$ & Phase II & $\begin{array}{l}\text { VTD } \\
\text { consolidation }\end{array}$ & 39 & $\begin{array}{l}\text { CR pre-VTD: } 15 \% \\
\text { CR post-VTD: } 49 \%\end{array}$ & $\begin{array}{l}\text { Median PFS: } \\
\text { 6o mon }\end{array}$ & $3-y r$ OS: $89 \%$ \\
\hline \multicolumn{7}{|c|}{ Lenalidomide-based } \\
\hline $\begin{array}{l}\text { Attal et al. } \\
(2012)[23]\end{array}$ & Phase III & $\begin{array}{l}\text { Len consolidation + } \\
\text { Len maintenance vs. } \\
\text { Len consolidation + } \\
\text { placebo }\end{array}$ & $\begin{array}{c}307 \text { vs. } \\
307\end{array}$ & $\begin{array}{l}\text { CR preconsolidation: } 58 \% \\
\text { CR postconsolidation: } 69 \% \\
(p<0.001)\end{array}$ & $\begin{array}{l}\text { NR after } \\
\text { consolidation }\end{array}$ & $\begin{array}{l}\text { NR after } \\
\text { consolidation }\end{array}$ \\
\hline $\begin{array}{l}\text { Roussel et al. } \\
(2014)[24]\end{array}$ & Phase II & RVD consolidation & 31 & $\begin{array}{l}\text { sCR/CR pre-VRD: } 47 \% \\
\text { sCR/CR post-VRD: } 50 \%\end{array}$ & 3-yr PFS: $77 \%$ & 3-yr OS: $100 \%$ \\
\hline
\end{tabular}

EFS, event-free survival; PFS, progression-free survival; OS, overall survival; VTD, bortezomib, thalidomide plus dexamethasone; TD, thalidomide plus dexamethasone; CR, complete response; nCR, near complete response; NS, non-specific; VGPR, very good partial response; TTP, time to progress; Len, lenalidomide; NR, not reached; RVD, lenalidomide, bortezomib plus dexamethasone; VRD, bortezomib, lenalidomide, and dexamethasone.

\section{MAINTENANCE THERAPY IN PATIENTS ELIGIBLE FOR TRANSPLANTATION}

Maintenance therapy is generally administered for a long duration and aims to improve PFS with minimal toxicity and without interfering with the QoL. The paradigm for transplant-eligible patients consists of induction, stemcell mobilization, and ASCT, followed by consolidation and/or maintenance [26]. Maintenance therapy consists of prolonged therapy of either a fixed duration or until progression to a sustained response. The ideal maintenance therapy is easily delivered, such as per oral, and a schedule administered intravenously is convenient for patients. This portion of the review focuses on maintenance therapy following ASCT for patients with transplant-eligible MM. The clinical outcomes of maintenance therapy for patients with transplant-eligible MM are summarized in Table 2 [17,23,27-37].

\section{Thalidomide}

Thalidomide maintenance studies have reported improved EFS or PFS compared with those with no maintenance. In the IFM study, Attal et al. [27] randomized 400 patients after ASCT to receive thalidomide versus no maintenance and demonstrated an improved 3-year EFS (52\% vs. 37\%, p< 0.009) and an improved 4-year OS (87\% vs. $75 \%, p<0.04)$. A single-institution study from Arkansas demonstrated a significant benefit of thalidomide vs. no thalidomide maintenance. The 5-year EFS was $64 \%$ for thalidomide and $43 \%$ for no maintenance $(p<0.001)$, and the 8-year OS was $57 \%$ for thalidomide versus $44 \%$ for no maintenance $(p=0.09)$ [28]. The Dutch-Belgian Hemato-Oncology Cooperative Group (HOVON)-5o study compared thalidomide and interferon- $\alpha$ (IFN- $\alpha$ ) maintenance and demonstrated that thalidomide improved median EFS (34 months vs. 22 months, $p<0.001$ ) but resulted in a non-significant increase in median OS (73 months vs. 60 months, $p=0.77$ ) [17]. The Medical Research Coun- 
Table 2. Maintenance therapy after autologous stem cell transplantation for newly diagnosed multiple myeloma

\begin{tabular}{|c|c|c|c|c|c|c|}
\hline Study & $\begin{array}{l}\text { Type of } \\
\text { trial }\end{array}$ & Treatment scheme & $\begin{array}{c}\text { No. of } \\
\text { patients }\end{array}$ & $\begin{array}{l}\text { Median } \\
\text { follow-up, } \\
\text { mon }\end{array}$ & EFS or PFS & OS \\
\hline \multicolumn{7}{|l|}{ Thalidomide-based } \\
\hline $\begin{array}{l}\text { Attal et al. } \\
(2006)[27]\end{array}$ & Phase III & $\begin{array}{l}\text { Pamidronate + thal vs. } \\
\text { pamidronate vs. } \\
\text { no maintenance }\end{array}$ & $\begin{array}{l}201 \text { vs. } 196 \\
\text { vs. } 200\end{array}$ & $\begin{array}{l}39 \text { vs. } 39 \\
\text { vs. } 40\end{array}$ & $\begin{array}{l}\text { 3-yr EFS: } 52 \% \\
\text { vs. } 37 \% \text { vs. } 36 \%\end{array}$ & $\begin{array}{l}\text { 4-yr OS: } 87 \% \\
\text { vs. } 74 \% \text { vs. } 77 \%\end{array}$ \\
\hline $\begin{array}{l}\text { Spencer et al. } \\
(2009)[31]\end{array}$ & Phase III & Thal + PRD vs. PRD & 243 & 36 & $\begin{array}{l}3-y r \text { PFS: } 42 \% \\
\text { vs. } 23 \%\end{array}$ & $\begin{array}{l}\text { 3-yr OS: } 86 \% \\
\text { vs. } 75 \%\end{array}$ \\
\hline $\begin{array}{l}\text { Maiolino et al. } \\
(2012)[32]\end{array}$ & Phase II & Thal + dexa vs. dexa & 56 vs. 52 & 27 & $\begin{array}{l}\text { 2-yr PFS: } 64 \% \\
\text { vs. } 30 \%\end{array}$ & $\begin{array}{l}2 \text {-yr OS: } 85 \% \\
\text { vs. } 70 \%\end{array}$ \\
\hline $\begin{array}{l}\text { Barlogie et al. } \\
(2008)[28]\end{array}$ & Phase III & $\begin{array}{l}\text { Thal }+ \text { IFN- } \alpha+\text { dexa vs. } \\
\text { IFN- } \alpha+\text { dexa }\end{array}$ & 323 vs. 345 & 72 & $\begin{array}{l}\text { 5-yr EFS: } 56 \% \\
\text { vs. } 45 \%\end{array}$ & $\begin{array}{l}\text { 5-yr OS: } 67 \% \\
\text { vs. } 65 \%\end{array}$ \\
\hline $\begin{array}{l}\text { Lokhorst et al. } \\
(2010)[17]\end{array}$ & Phase III & Thal vs. IFN- $\alpha$ & 268 vs. 268 & 52 & $\begin{array}{l}\text { Median PFS: } \\
34 \text { mon vs. } 25 \text { mon }\end{array}$ & $\begin{array}{l}\text { Median OS: } \\
73 \text { mon vs. } 60 \text { mon }\end{array}$ \\
\hline $\begin{array}{l}\text { Stewart et al. } \\
(2013)[30]\end{array}$ & Phase III & $\begin{array}{l}\text { Thal + PRD vs. } \\
\text { no maintenance }\end{array}$ & 166 vs. 166 & 48 & $\begin{array}{l}\text { Median PFS: } \\
28 \text { mon vs. } 17 \text { mon }\end{array}$ & $\begin{array}{l}\text { 4-yr OS: } 68 \% \\
\text { vs. } 60 \%\end{array}$ \\
\hline $\begin{array}{l}\text { Morgan et al. } \\
(2012)[29]\end{array}$ & Phase III & Thal vs. no maintenance & 245 vs. 247 & 46 & $\begin{array}{l}\text { Median PFS: } \\
30 \text { mon vs. } 23 \text { mon }\end{array}$ & $\begin{array}{l}\text { 3-yr OS: } 75 \% \\
\text { vs. } 80 \%\end{array}$ \\
\hline \multicolumn{7}{|l|}{ Bortezomib-based } \\
\hline $\begin{array}{l}\text { Sonneveld et al. } \\
(2012)[33]\end{array}$ & Phase III & $\begin{array}{l}\text { Bortezomib } 1.3 \mathrm{mg} / \mathrm{m}^{2} \\
\text { every } 2 \mathrm{wk} \text { vs. } \\
\text { thal } 50 \mathrm{mg} / \text { day }\end{array}$ & 160 vs. 161 & 74 & $\begin{array}{l}\text { Median PFS: } \\
36 \text { mon vs. } 27 \text { mon }\end{array}$ & $\begin{array}{l}\text { Median OS: NR } \\
\text { vs. } 84 \text { mon }\end{array}$ \\
\hline $\begin{array}{l}\text { Rosinol et al. } \\
(2012)[34]\end{array}$ & Phase III & VT vs. T vs. IFN- $\alpha-2 b$ & $\begin{array}{l}89 \text { vs. } 87 \\
\text { vs. } 90\end{array}$ & 34.9 & $\begin{array}{l}\text { Median PFS: } \\
56.2 \text { mon vs. } 35 \cdot 3 \\
\text { mon vs. } 28.2 \text { mon }\end{array}$ & $\begin{array}{l}4 \text {-yr OS: } 74 \% \\
\text { vs. } 70 \% \text { vs. } 65 \%\end{array}$ \\
\hline \multicolumn{7}{|c|}{ Lenalidomide-based } \\
\hline $\begin{array}{l}\text { Attal et al. } \\
(2012)[23]\end{array}$ & Phase III & $\begin{array}{l}\text { Len } 10 \mathrm{mg} / \text { day } \\
\text { vs. placebo }\end{array}$ & 307 vs. 307 & 45 & $\begin{array}{l}\text { Median EFS: } \\
40 \text { mon vs. } 23 \text { mon }\end{array}$ & $\begin{array}{l}\text { 4-yr OS: } 73 \% \\
\text { vs. } 75 \%\end{array}$ \\
\hline $\begin{array}{l}\text { McCarthy et al. } \\
(2012)[35]\end{array}$ & Phase III & $\begin{array}{l}\text { Len } 10 \text { mg/day } \\
\text { vs. placebo }\end{array}$ & 230 vs. 230 & 34 & $\begin{array}{l}\text { Median TTP: } \\
46 \text { mon vs. } 27 \text { mon }\end{array}$ & $\begin{array}{l}\text { 3-yr OS: } 88 \% \\
\text { vs. } 80 \%\end{array}$ \\
\hline $\begin{array}{l}\text { Palumbo et al. } \\
(2014)[36]\end{array}$ & Phase III & $\begin{array}{l}\text { Len } 10 \mathrm{mg} / \text { day } \\
\text { vs. placebo }\end{array}$ & 126 vs. 125 & 51.2 & $\begin{array}{l}\text { Median PFS: } \\
41.9 \text { mon vs. } 21.6 \text { mon }\end{array}$ & $\begin{array}{l}3 \text {-yr OS: } 88 \% \\
\text { vs. } 79.2 \%\end{array}$ \\
\hline $\begin{array}{l}\text { Gay et al. } \\
(2015)[37]\end{array}$ & Phase III & $\begin{array}{l}\text { Len } 10 \text { mg/day + } \\
\text { PRD vs. Len } 10 \text { mg/day }\end{array}$ & 117 vs. 106 & 52 & $\begin{array}{l}\text { Median PFS: } \\
37.5 \text { mon vs. } 28.5 \text { mon }\end{array}$ & $\begin{array}{l}3-y r \text { OS: } 83 \% \\
\text { vs. } 88 \%\end{array}$ \\
\hline
\end{tabular}

EFS, event-free survival; PFS, progression-free survival; OS, overall survival; thal, thalidomide; PRD, prednisone; dexa, dexamethasone; IFN- $\alpha$, interferon- $\alpha$; NR, not reached; VT, bortezomib plus thalidomide; T, thalidomide; Len, lenalidomide; TTP, time to progression.

cil of the United Kingdom Myeloma IX study examined transplant and non-transplant approaches to treat newly diagnosed patients with MM. Thalidomide maintenance for the transplant arm resulted in a median PFS of 22 months versus 15 months for the no-maintenance arm $(p<0.0001)$. Median OS was 60 months in both groups $(p=0.70)$ [29]. Median PFS only improved due to thalidomide maintenance in patients with low-risk disease according to the cytogenetic analysis at diagnosis
(29 months vs. 18 months, $p=0.01$ ), but no OS benefit was observed. Thalidomide plus glucocorticoids has been investigated as maintenance after ASCT [30-32]. An Australian study compared 243 patients receiving 1 year of thalidomide with prednisolone until progression to patients receiving prednisolone alone until progression [31]. The 3-year PFS was $42 \%$ for the thalidomide/prednisolone (TP) arm and $23 \%$ for the prednisolone-only arm $(p<0.001)$. The 3 -year OS was $86 \%$ for the TP 
arm and $75 \%$ for the prednisolone-only arm $(p=0.004)$. The National Cancer Institute of Canada Clinical Trials Group and the Eastern Cooperative Oncology Group maintenance study randomized 332 patients with MM receiving a single ASCT to TP versus observation after ASCT [30]. The PFS of patients who received TP was superior to that of observation (4-year estimates: $32 \%$ vs. $14 \%, p<0.0001)$. At a median follow-up of 4 years, the OS was $68 \%$ for thalidomide and prednisone and $60 \%$ for observation ( $p=0.18$ ). Thalidomide maintenance may be an effective option for patients with transplant-eligible MM, and thalidomide should be administered at the minimal effective dose and possibly for no longer than 1 year.

\section{Bortezomib}

The HOVON and German Multicenter Myeloma Group randomized 827 symptomatic patients and those with newly diagnosed MM to either VAD or bortezomib, doxorubicin, and dexamethasone (PAD) [33]. The study was reported at a median follow-up of 41 months. Median PFS of the PAD-P (bortezomib maintenance) arm was 36 months, and that of the VAD-T (thalidomide maintenance) arm was 27 months $(p=0.002)$. The Spanish Myeloma group (Grupo Espanol de Mieloma PETHEMA) conducted a 386-patient trial that randomized newly diagnosed patients with MM into induction treatments of VTD versus TD versus alternating chemotherapy of vincristine, carmustine, melphalan, cyclophosphamide, prednisone/ vincristine, carmustine, doxorubicin, or dexamethasone [34]. All three groups were randomized to maintenance therapy for 3 years with IFN- $\alpha$ versus thalidomide or bortezomib plus thalidomide (VT). At a median follow-up of 2 years from initiating maintenance therapy, the 3-year PFS of the VT maintenance treatment was significantly longer than that of the thalidomide or IFN- $\alpha$ (78\% vs. $63 \%$ vs. $49 \%, p=0.01$ ). No difference in OS was observed among the three arms (Table 2).

\section{Lenalidomide}

Three phase 3 studies have examined lenalidomide maintenance therapy after ASCT (Table 2) [23,35,36]. The Cancer and Leukemia Group B (CALGB) 100104 study randomized 462 patients with newly diagnosed MM who had received various induction regimens to $10 \mathrm{mg}$ of lenalidomide daily (dose range, 5 to $15 \mathrm{mg}$ ) versus pla- cebo until progression after single ASCT [35]. The 3-year PFS was 66\% for the lenalidomide arm and $39 \%$ for the placebo arm $(p<0.001)$. The 3-year OS for the lenalidomide arm with a median follow-up of 34 months was $88 \%$, and that of the placebo arm was $80 \%(p=0.028)$. The IFM 05-02 study examined 605 patients randomized to lenalidomide in the same dose range as that used in the CALGB 100104 versus placebo study until progression after single (79\%) or double ASCT (21\%). Four-year PFS rates were $43 \%$ for the lenalidomide-arm and $22 \%$ for the placebo-arm patients $(p<0.001)$; no difference in OS was detected between the arms. The 4-year OS rate was $73 \%$ for the lenalidomide arm and $75 \%$ for the placebo arm $(p=0.7)$. A third lenalidomide maintenance study compared melphalan, prednisone, and lenalidomide (MPR) vs. tandem ASCT with high-dose melphalan [36]. The chemotherapy and tandem ASCT maintenance patients were combined and compared with the chemotherapy and tandem ASCT patients who did not receive lenalidomide maintenance. At a median follow-up of 51.2 months from chemotherapy or tandem ASCT, median PFS was 41.9 months for the lenalidomide maintenance patients and 21.6 months for patients who did not receive maintenance $(p<0.0001)$. The 3 -year OS estimate was $88.0 \%$ for the lenalidomide arm and $79.2 \%$ for the no-maintenance arm $(p=0.14)$. Gay et al. [37] examined maintenance therapy with lenalidomide plus prednisone versus lenalidomide alone following cyclophosphamide, lenalidomide, prednisone versus tandem ASCT in 389 patients with newly diagnosed MM. At a median follow-up of 52 months from chemotherapy or tandem ASCT, PFS did not differ between maintenance treatments with lenalidomide plus prednisone versus with lenalidomide alone ( 37.5 months vs. 28.5 months, $p=0.34)$. Three-year OS in the 223 patients eligible for maintenance did not differ between the lenalidomide plus prednisone and lenalidomide alone groups $(83 \%$ vs. $88 \%, p=0.21$ ).

\section{SOUTH KOREAN STUDY OF THALIDOMIDE MAINTENANCE IN CLINICAL PRACTICE}

Some concerns have been raised about applying thalidomide maintenance in patients with MM who are eligible for ASCT in an actual clinical setting. Lee et al. [38] 
reported on the clinical impact of thalidomide maintenance after ASCT in a South Korean clinical practice. The 3-year PFS rates of patients treated with and without maintenance were $55.4 \%$ and $37.2 \%$, respectively $(p=$ 0.005). The 3-year OS rates of patients treated with and without maintenance were $88.0 \%$ and $84.0 \%$, respectively $(p=0.105)$. The 3-year OS rates after relapse or progression of patients treated with and without maintenance were $50.4 \%$ and $55.3 \%$, respectively $(p=0.661)$. In particular, patients who showed less than a CR after ASCT and who had undergone maintenance therapy had superior survival rates to those who had not received such therapy. Among the patients who showed less than CR after ASCT, the 3-year PFS rates with and without maintenance therapy were $68.4 \%$ and $23.3 \%$ ( $p<0.001$ ), respectively. Thalidomide maintenance after ASCT can be helpful to prolong PFS in fit patients with MM. Longterm exposure to thalidomide during maintenance therapy may not affect survival after relapse or progression from salvage chemotherapy. Finally, patients who have shown less than CR after ASCT might have the option of undergoing thalidomide maintenance.

\section{MAINTENANCE THERAPY IN PATIENTS INELI- GIBLE FOR TRANSPLANTATION}

Patients $\geq 65$ years of age do not tolerate intensive therapy and are usually ineligible for ASCT. Combinations with novel agents, such as thalidomide, lenalidomide, and bortezomib, are widely adopted for newly diagnosed and relapsed patients with MM. The clinical outcomes of maintenance therapy for patients with transplant-ineligible MM are summarized in Table 3 [39-51].

\section{Thalidomide}

Thalidomide can be a suitable option for prolonged use because it is administered orally. Continuous thalidomide therapy after induction with melphalan-prednisone-thalidomide (MPT) has been evaluated for transplant-ineligible patients in six trials (Table 3). In one study, $100 \mathrm{mg} /$ day thalidomide was given continuously. Median PFS was 22 months for patients who received thalidomide and 15 months for those who did not $(p<$ o.001). Median OS rates were 48 and 45 months for the two arms, respectively $(p=0.79)$ [39]. In another study,
$200 \mathrm{mg} /$ day thalidomide was administered at induction and was reduced to $50 \mathrm{mg} /$ day during maintenance. Median EFS was 13 months for patients who received thalidomide and 9 months for those who did not $(p<0.001)$. A marginally significant OS advantage favoring thalidomide maintenance was also detected, with median OS of 40 months versus 31 months $(p=0.05)$ [40]. In another study, $200 \mathrm{mg} /$ day thalidomide was administered continuously until relapse [41]. Median PFS (15 months vs. 14 months, $p=0.84$ ) and OS (29 months vs. 32 months, $p$ $=0.16$ ) were similar between patients who received thalidomide and those who did not. Finally, another study randomized 820 patients including those who were and were not eligible for ASCT to thalidomide maintenance or no maintenance. Patients ineligible for ASCT had received MP or cyclophosphamide-TD induction [29]. In these patients, thalidomide maintenance improved PFS (23 months vs. 15 months, $p<0.001$ ), but median OS was not different between the two arms $(p=0.40)$. All studies including thalidomide maintenance reported improved PFS, although a longer follow-up was needed to detect an OS benefit. These findings support the concept that thalidomide maintenance should be administered at the minimal effective dose associated with the lowest toxicity (50 to $100 \mathrm{mg} /$ day) to avoid early discontinuation.

\section{Bortezomib}

Bortezomib is another possible option as maintenance therapy. In one study, bortezomib plus either thalidomide (VT) or prednisone (VP) was administered after induction with either VMP or bortezomib-thalidomide-prednisone [42]. Median PFS tended to be longer with VT ( 32 months) than with $\operatorname{VP}(24$ months $)(p=0.1)$. In another study, bortezomib-melphalan-prednisone-thalidomide (VMPT) induction followed by VT maintenance (VMPT-VT) was compared with VMP followed by no maintenance [43,44]. VT consisted of $1.3 \mathrm{mg} / \mathrm{m}^{2}$ bortezomib every 15 days and $50 \mathrm{mg} /$ day thalidomide for 2 years or until progression or relapse. Median PFS was significantly longer with VMPT-VT (35.3 months) than with VMP (24.8 months, $p<0.001)$. The 5 -year OS was greater with VMPT-VT (61\%) than that with VMP (51\%, $p=0.01)$. Another study assessed the role of bortezomib alone as maintenance therapy $\left(1.6 \mathrm{mg} / \mathrm{m}^{2}\right.$, days $1,8,15$, and 22 for five 35-day cycles) after induction with VD, VTD, or VMP [45]. Median PFS was 14.7 months with 
Table 3. Maintenance therapy for patients ineligible for autologous stem cell transplantation

\begin{tabular}{|c|c|c|c|c|c|c|}
\hline Study & $\begin{array}{l}\text { Type of } \\
\text { trial }\end{array}$ & $\begin{array}{l}\text { Treatment } \\
\text { scheme }\end{array}$ & $\begin{array}{l}\text { No. of } \\
\text { patients }\end{array}$ & $\begin{array}{l}\text { Median } \\
\text { follow-up, } \\
\text { mon }\end{array}$ & $\begin{array}{l}\text { EFS or PFS, } \\
\text { mon }\end{array}$ & OS \\
\hline \multicolumn{7}{|l|}{ Thalidomide-based } \\
\hline Palumbo et al. (2008) [39] & Phase III & MPT vs. MP & 129 vs. 126 & 38.1 & 21.8 vs. 14.5 & 45 mon vs. 47.6 mon \\
\hline Facon et al. (2007) [49] & Phase III & MPT vs. MP & 191 vs. 124 & 51.5 & 27.5 vs. 17.8 & 51.6 mon vs. 33.2 mon \\
\hline Hulin et al. (2009) [50] & Phase III & MPT vs. MP & 113 vs. 116 & $47 \cdot 5$ & 24.1 VS. 18.5 & 44 mon vs. 29.1 mon \\
\hline Waage et al. (2010) [41] & Phase III & MPT vs. MP & 182 vs. 175 & 36 & 15 vs. 14 & 29 mon vs. 32 mon \\
\hline Wijermans et al. (2010) [40] & Phase III & MPT vs. MP & 165 vs. 168 & & $\begin{array}{l}\text { EFS: } 13 \text { vS. } 9 \\
\text { PFS: } 15 \text { Vs. } 11\end{array}$ & 40 mon vs. 31 mon \\
\hline Beksac et al. (2011) [51] & Phase III & MPT vs. MP & 62 vs. 60 & 23 & DFS: 21 vs. 14 & 26 mon vs. 28 mon \\
\hline \multicolumn{7}{|l|}{ Bortezomib-based } \\
\hline $\begin{array}{l}\text { Palumbo et al. (2014) [43], } \\
(2010)[44]\end{array}$ & Phase III & $\begin{array}{l}\text { VMPT vs. VMP } \\
\rightarrow \text { BT vs. No }\end{array}$ & 511 & 54 & 35.3 vs. 24.8 & 5 -yr OS: $61 \%$ vs. $51 \%$ \\
\hline Mateos et al. (2010) [42] & Phase III & $\begin{array}{l}\text { VMP vs. VTP } \\
\rightarrow \text { BT vs. BP }\end{array}$ & 260 & 46 & 39 vs. 32 & NR vs. 60 mon \\
\hline Niesvizky et al. (2015) [45] & Phase IIIb & $\begin{array}{l}\text { VD vs. VTD } \\
\text { vs. VMP }\end{array}$ & 502 & 42.7 & $\begin{array}{l}14.7 \text { vs. } 15 \cdot 4 \\
\text { vs. } 17 \cdot 3\end{array}$ & $\begin{array}{l}49.8 \text { mon vs. } 51.5 \text { mon } \\
\text { vs. } 53.1 \text { mon }\end{array}$ \\
\hline \multicolumn{7}{|l|}{ Lenalidomide-based } \\
\hline Palumbo et al. (2012) [46] & Phase III & $\begin{array}{l}\text { MPR-R vs. } \\
\text { MPR vs. MP } \rightarrow \text { Len }\end{array}$ & 459 & 30 & 31 vs. 14 Vs. 13 & $\begin{array}{l}\text { 3-yr OS: } 70 \% \text { vs. } 62 \% \\
\text { vs. } 66 \%\end{array}$ \\
\hline Benboubker et al. (2014) [47] & Phase III & $\begin{array}{l}\text { Ld cont vs. } \\
\text { Ld } 18 \text { vs. MPT }\end{array}$ & $\begin{array}{c}535 \text { vs. } \\
541 \text { vs. } 547\end{array}$ & 37 & $\begin{array}{l}25.5 \text { VS. } 20.7 \\
\text { VS. } 21.2\end{array}$ & $\begin{array}{l}4 \text {-yr OS: } 59 \% \text { vs. } 56 \% \\
\text { vs. } 51 \%\end{array}$ \\
\hline Zweegman et al. (2016) [48] & Phase III & MPT-T vs. MPR-R & 688 & 36 & 20 vs. 23 & 4-yr OS: $52 \%$ vs. $56 \%$ \\
\hline
\end{tabular}

EFS, event-free survival; PFS, progression-free survival; OS, overall survival; MPT, melphalan, prednisone, and thalidomide; MP, melphalan and prednisone; DFS, disease-free survival; VMPT, bortezomib, melphalan, prednisone, and thalidomide; VMP, bortezomib, melphalan, and prednisone; BT, bortezomib and thalidomide; BP, bortezomib and prednisone; NR, not reached; VD, bortezomib and dexamethasone; VTD, bortezomib, thalidomide, plus dexamethasone; MPR-R, melphalan, prednisone, and lenalidomide and then lenalidomide maintenance; MPR, melphalan, prednisone, and lenalidomide; Len, lenalidomide; Ld cont, lenalidomide and dexamethasone continuous treatment; Ld18, lenalidomide and dexamethasone until 18 cycles; MPT-T, melphalan, prednisone, and thalidomide and then thalidomide maintenance.

VD, 15.4 months with VTD, and 17.3 months with VMP. The respective median OS rates were $49.8,51.5$, and 53.1 months, respectively.

\section{Lenalidomide}

A phase 3 study evaluated the role of $10 \mathrm{mg}$ of lenalidomide on days 1 to 21 of each 28-day cycle after melphalan-prednisone-lenalidomide (MPR-R) versus MPR versus MP [46]. In a landmark analysis from the start of lenalidomide maintenance, lenalidomide after MPR significantly prolonged median PFS from 7 to 26 months ( $p$ $<0.001$ ). However, 4-year OS was approximately $58 \%$ in the three treatment groups. A recent large phase 3 study compared lenalidomide plus low-dose dexamethasone (Rd) until relapse versus $\mathrm{Rd}$ for 18 cycles (72 weeks) versus
MPT for 12 cycles (72 weeks) [47]. After a median follow-up of 37 months, Rd significantly improved PFS compared with MPT $(p=0.00006)$ and marginally improved OS $(p=$ 0.01685 ). These results suggest the need for continuous Rd because the outcomes after 18 cycles of therapy were similar between Rd and MPT. Finally, Zweegman et al. [48] randomly assigned 668 patients to a group with nine 4-week cycles of MPT followed by thalidomide maintenance until disease progression or unacceptable toxicity (MPT-T) or to a group with the same MP regimen but with thalidomide replaced with lenalidomide (MPR-R). After a median follow-up of 36 months, PFS was 20 months with MPT-T versus 23 months with MPR-R $(p=0.12)$. OS rates at 2, 3, and 4 years in the MPT-T and MPR-R arms were $73 \%$ versus $84 \%, 64 \%$ versus $69 \%$, and $52 \%$ versus $56 \%$, respective- 
ly $(p=0.13)$. Based on these data, lenalidomide seems to be the most suitable choice for maintenance and may be preferable over thalidomide because of its higher efficacy.

\section{CONSIDERATIONS IN THE MAINTENANCE SETTING}

\section{Toxicities}

Toxicity considerations have an important role in any therapy, although application in long-term therapy is attractive from an efficacy point of view. In a meta-analysis of thalidomide maintenance trials conducted by Kagoya et al. [52], thalidomide resulted in more venous thrombosis and peripheral neuropathy (PN) compared with those of the control treatment. Bortezomib therapy can also lead to PN, although a number of strategies to improve tolerability can be followed. Specifically, bortezomib dosing can be reduced to once weekly or fortnightly, and the subcutaneous formulation can be used, which has demonstrated comparable efficacy to the intravenous formulation but with a substantially reduced frequency of PN [53].

\section{Second primary malignancy}

Long-term administration of lenalidomide increases the risk of developing hematological second primary malignancy (SPM), which was demonstrated in an analysis of nine clinical trials involving 3,254 patients [54]. However, the PFS benefit associated with lenalidomide maintenance outweighs the increased risk of SPM. A recent meta-analysis of 3,218 patients reported that patients treated with lenalidomide have an increased risk of developing hematologic SPM (hazard ratio [HR], 1.55; $p$ $=0.037$ ) . Notably, risk increased when lenalidomide was paired with melphalan compared with melphalan alone (HR, 4.86; $p<0.0001$ ), whereas exposure to lenalidomide plus cyclophosphamide (HR, 1.26; $p=0.75)$ or lenalidomide plus dexamethasone ( $\mathrm{HR}, 0.86 ; p=0.76$ ) did not increase hematologic SPM risk versus melphalan alone [54]. In the CALGB 100104 study [35], eight of 231 (3.5\%) patients in the lenalidomide arm developed a hematologic malignancy or primarily myeloid malignancies (acute myeloid leukemia/myelodysplastic syndrome, $\mathrm{n}=$ 6), whereas only one of 229 (0.4\%) in the placebo arm developed such a malignancy (non-Hodgkin's lymphoma, $\mathrm{n}=1$ ). When counting events of progression, death, and SPM, the median EFS was 43 months for the lenalidomide arm and 27 months for the placebo arm $(p<0.001)$.

\section{Quality of life}

When administering therapy for a prolonged period of time, QoL considerations become important. To date, only a few studies have analyzed the impact of consolidation or maintenance therapy on QoL. Stewart et al. [30] found that applying TP following ASCT had a substantial negative impact on QoL, with patients reporting worse QoL with respect to cognitive function, dyspnea, constipation, thirst, leg swelling, numbness, dry mouth, and balance problems. In contrast, Mellqvist et al. [21] reported that applying bortezomib consolidation did not reduce QoL. Toxicities, such as fatigue, nausea/ vomiting, and $\mathrm{PN}$, can be effectively managed with a reduction in dosing frequency or changing the route of administration. Nevertheless, more data are needed to elucidate the effect of long-term therapy on QoL.

\section{Minimal residual disease}

Depth of response as manifested by the presence or absence of MRD is correlated with long-term disease control $[20,55]$. However, factors such as disease staging, cytogenetics, and gene expression profiling predict long-term outcome [56]. Thus, there have been attempts to incorporate cytogenetic risk factors and detection of MRD [57].

\section{CONCLUSIONS}

To date, all available studies have demonstrated that novel agent-based consolidation therapy enhances the frequency and depth of response achieved during previous treatment phases, including either single or double ASCT. The enhanced rate and quality of responses offered by consolidation therapy contribute to the improved clinical outcomes including extending PFS. Maintenance therapy is an effective strategy to prolong remission duration and survival in young and elderly patients. In the era of novel agents, various maintenance approaches have been tested and are associated with a PFS advantage. Single agents, such as thalidomide, lenalidomide, or bortezomib maintenance, are well 
tolerated, and each can be safely used as part of a sequential approach after induction and transplantation. Thalidomide maintenance is also a valuable option in elderly patients, although PN remains a serious problem. Lenalidomide is advantageous because it is not neurologically toxic and is a valuable option after lenalidomide-containing induction chemotherapy. Bortezomib maintenance also seems to improve treatment outcomes when used with a reduced schedule to decrease the frequency of PN. However, limitations, such as cost of drugs, toxicities, and QoL, should be considered in clinical practice compared with a clinical trial setting.

\section{Conflict of interest}

No potential conflict of interest relevant to this article was reported.

\section{REFERENCES}

1. Kyle RA, Rajkumar SV. Multiple myeloma. N Engl J Med 2004;351:1860-1873.

2. International Myeloma Working Group. Criteria for the classification of monoclonal gammopathies, multiple myeloma and related disorders: a report of the International Myeloma Working Group. Br J Haematol 2003;121:749-757.

3. Palumbo A, Cerrato C. Diagnosis and therapy of multiple myeloma. Korean J Intern Med 2013;28:263-273.

4. Yi JE, Lee SE, Jung HO, Min CK, Youn HJ. Association between left ventricular function and paraprotein type in patients with multiple myeloma. Korean J Intern Med 2016 Apr 6 [Epub]. http://dx.doi.org/10.3904/kjim.2015.339.

5. Attal M, Harousseau JL, Stoppa AM, et al. A prospective, randomized trial of autologous bone marrow transplantation and chemotherapy in multiple myeloma: Intergroupe Francais du Myelome. N Engl J Med 1996;335:91-97.

6. Attal M, Harousseau JL, Facon T, et al. Single versus double autologous stem-cell transplantation for multiple myeloma. N Engl J Med 2003;349:2495-2502.

7. Gentile M, Vigna E, Recchia AG, Morabito L, Martino M, Morabito F. Role of new drugs incorporated into consolidation and maintenance therapy in transplant-eligible multiple myeloma patients. Expert Opin Pharmacother 2014;15:1315-1320.

8. Cavo M, Pantani L, Petrucci MT, et al. Bortezomib-thalid- omide-dexamethasone is superior to thalidomide-dexamethasone as consolidation therapy after autologous hematopoietic stem cell transplantation in patients with newly diagnosed multiple myeloma. Blood 2012;120:9-19.

9. Usmani SZ, Crowley J, Hoering A, et al. Improvement in long-term outcomes with successive total therapy trials for multiple myeloma: are patients now being cured? Leukemia 2013;27:226-232.

10. Cavo M, Brioli A, Tacchetti P, Zannetti BA, Mancuso $\mathrm{K}$, Zamagni E. Role of consolidation therapy in transplant eligible multiple myeloma patients. Semin Oncol 2013;40:610-617.

11. McCarthy PL, Einsele H, Attal M, Giralt S. The emerging role of consolidation and maintenance therapy for transplant-eligible multiple myeloma patients. Expert Rev Hematol 2014;7:55-66.

12. Ludwig H, Durie BG, McCarthy P, et al. IMWG consensus on maintenance therapy in multiple myeloma. Blood 2012;119:3003-3015.

13. Mohty M, Richardson PG, McCarthy PL, Attal M. Consolidation and maintenance therapy for multiple myeloma after autologous transplantation: where do we stand? Bone Marrow Transplant 2015;50:1024-1029.

14. Cavo M, Zamagni E, Tosi P, et al. Superiority of thalidomide and dexamethasone over vincristine-doxorubicindexamethasone (VAD) as primary therapy in preparation for autologous transplantation for multiple myeloma. Blood 2005;106:35-39.

15. Rajkumar SV, Blood E, Vesole D, Fonseca R, Greipp PR; Eastern Cooperative Oncology Group. Phase III clinical trial of thalidomide plus dexamethasone compared with dexamethasone alone in newly diagnosed multiple myeloma: a clinical trial coordinated by the Eastern Cooperative Oncology Group. J Clin Oncol 2006;24:431-436.

16. Harousseau JL, Attal M, Avet-Loiseau H, et al. Bortezomib plus dexamethasone is superior to vincristine plus doxorubicin plus dexamethasone as induction treatment prior to autologous stem-cell transplantation in newly diagnosed multiple myeloma: results of the IFM 2005-01 phase III trial. J Clin Oncol 2010;28:4621-4629.

17. Lokhorst HM, van der Holt B, Zweegman S, et al. A randomized phase 3 study on the effect of thalidomide combined with adriamycin, dexamethasone, and high-dose melphalan, followed by thalidomide maintenance in patients with multiple myeloma. Blood 2010;115:1113-1120.

18. Morgan GJ, Davies FE, Gregory WM, et al. Cyclophos- 
phamide, thalidomide, and dexamethasone as induction therapy for newly diagnosed multiple myeloma patients destined for autologous stem-cell transplantation: MRC Myeloma IX randomized trial results. Haematologica 2012;97:442-450.

19. Barlogie B, Anaissie E, Haessler J, et al. Complete remission sustained 3 years from treatment initiation is a powerful surrogate for extended survival in multiple myeloma. Cancer 2008;113:355-359.

20. Rawstron AC, Child JA, de Tute RM, et al. Minimal residual disease assessed by multiparameter flow cytometry in multiple myeloma: impact on outcome in the Medical Research Council Myeloma IX Study. J Clin Oncol 2013;31:2540-2547.

21. Mellqvist UH, Gimsing P, Hjertner O, et al. Bortezomib consolidation after autologous stem cell transplantation in multiple myeloma: a Nordic Myeloma Study Group randomized phase 3 trial. Blood 2013;121:4647-4654.

22. Ladetto M, Pagliano G, Ferrero S, et al. Major tumor shrinking and persistent molecular remissions after consolidation with bortezomib, thalidomide, and dexamethasone in patients with autografted myeloma. J Clin Oncol 2010;28:2077-2084.

23. Attal M, Lauwers-Cances V, Marit G, et al. Lenalidomide maintenance after stem-cell transplantation for multiple myeloma. N Engl J Med 2012;366:1782-1791.

24. Roussel M, Lauwers-Cances V, Robillard N, et al. Frontline transplantation program with lenalidomide, bortezomib, and dexamethasone combination as induction and consolidation followed by lenalidomide maintenance in patients with multiple myeloma: a phase II study by the Intergroupe Francophone du Myelome. J Clin Oncol 2014;32:2712-2717.

25. Leleu X, Fouquet G, Hebraud B, et al. Consolidation with VTd significantly improves the complete remission rate and time to progression following VTd induction and single autologous stem cell transplantation in multiple myeloma. Leukemia 2013;27:2242-2244.

26. McCarthy PL, Hahn T. Strategies for induction, autologous hematopoietic stem cell transplantation, consolidation, and maintenance for transplantation-eligible multiple myeloma patients. Hematology Am Soc Hematol Educ Program 2013;2013:496-503.

27. Attal M, Harousseau JL, Leyvraz S, et al. Maintenance therapy with thalidomide improves survival in patients with multiple myeloma. Blood 2006;108:3289-3294.
28. Barlogie B, Pineda-Roman M, van Rhee F, et al. Thalidomide arm of total therapy 2 improves complete remission duration and survival in myeloma patients with metaphase cytogenetic abnormalities. Blood 2008;112:3115-3121.

29. Morgan GJ, Gregory WM, Davies FE, et al. The role of maintenance thalidomide therapy in multiple myeloma: MRC myeloma IX results and meta-analysis. Blood 2012;119:7-15.

30. Stewart AK, Trudel S, Bahlis NJ, et al. A randomized phase 3 trial of thalidomide and prednisone as maintenance therapy after ASCT in patients with MM with a quality-of-life assessment: the National Cancer Institute of Canada Clinicals Trials Group Myeloma 10 Trial. Blood 2013;121:1517-1523.

31. Spencer A, Prince HM, Roberts AW, et al. Consolidation therapy with low-dose thalidomide and prednisolone prolongs the survival of multiple myeloma patients undergoing a single autologous stem-cell transplantation procedure. J Clin Oncol 2009;27:1788-1793.

32. Maiolino A, Hungria VT, Garnica M, et al. Thalidomide plus dexamethasone as a maintenance therapy after autologous hematopoietic stem cell transplantation improves progression-free survival in multiple myeloma. Am J Hematol 2012;87:948-952.

33. Sonneveld P, Schmidt-Wolf IG, van der Holt B, et al. Bortezomib induction and maintenance treatment in patients with newly diagnosed multiple myeloma: results of the randomized phase III HOVON-65/ GMMG-HD4 trial. J Clin Oncol 2012;30:2946-2955.

34. Rosinol L, Oriol A, Teruel AI, et al. Superiority of bortezomib, thalidomide, and dexamethasone (VTD) as induction pretransplantation therapy in multiple myeloma: a randomized phase 3 PETHEMA/GEM study. Blood 2012;120:1589-1596.

35. McCarthy PL, Owzar K, Hofmeister CC, et al. Lenalidomide after stem-cell transplantation for multiple myeloma. N Engl J Med 2012;366:1770-1781.

36. Palumbo A, Cavallo F, Gay F, et al. Autologous transplantation and maintenance therapy in multiple myeloma. $\mathrm{N}$ Engl J Med 2014;371:895-905.

37. Gay F, Oliva S, Petrucci MT, et al. Chemotherapy plus lenalidomide versus autologous transplantation, followed by lenalidomide plus prednisone versus lenalidomide maintenance, in patients with multiple myeloma: a randomised, multicentre, phase 3 trial. Lancet Oncol 2015;16:1617-1629. 
38. Lee HS, Min CK, Lee JJ, et al. The clinical impact of thalidomide maintenance after autologous stem cell transplantation in patients with newly diagnosed multiple myeloma in real clinical practice of Korea. Ann Hematol 2016;95:911-919.

39. Palumbo A, Bringhen S, Liberati AM, et al. Oral melphalan, prednisone, and thalidomide in elderly patients with multiple myeloma: updated results of a randomized controlled trial. Blood 2008;112:3107-3114.

40. Wijermans P, Schaafsma M, Termorshuizen F, et al. Phase III study of the value of thalidomide added to melphalan plus prednisone in elderly patients with newly diagnosed multiple myeloma: the HOVON 49 study. J Clin Oncol 2010;28:3160-3166.

41. Waage A, Gimsing P, Fayers P, et al. Melphalan and prednisone plus thalidomide or placebo in elderly patients with multiple myeloma. Blood 2010;116:1405-1412.

42. Mateos MV, Oriol A, Martinez-Lopez J, et al. Bortezomib, melphalan, and prednisone versus bortezomib, thalidomide, and prednisone as induction therapy followed by maintenance treatment with bortezomib and thalidomide versus bortezomib and prednisone in elderly patients with untreated multiple myeloma: a randomised trial. Lancet Oncol 2010;11:934-941.

43. Palumbo A, Bringhen S, Larocca A, et al. Bortezomib-melphalan-prednisone-thalidomide followed by maintenance with bortezomib-thalidomide compared with bortezomib-melphalan-prednisone for initial treatment of multiple myeloma: updated follow-up and improved survival. J Clin Oncol 2014;32:634-640.

44. Palumbo A, Bringhen S, Rossi D, et al. Bortezomib-melphalan-prednisone-thalidomide followed by maintenance with bortezomib-thalidomide compared with bortezomib-melphalan-prednisone for initial treatment of multiple myeloma: a randomized controlled trial. J Clin Oncol 2010;28:5101-5109.

45. Niesvizky R, Flinn IW, Rifkin R, et al. Community-based phase IIIB trial of three UPFRONT bortezomib-based myeloma regimens. J Clin Oncol 2015;33:3921-3929.

46. Palumbo A, Hajek R, Delforge M, et al. Continuous lenalidomide treatment for newly diagnosed multiple myeloma. N Engl J Med 2012;366:1759-1769.

47. Benboubker L, Dimopoulos MA, Dispenzieri A, et al. Lenalidomide and dexamethasone in transplant-ineligible patients with myeloma. N Engl J Med 2014;371:906-917.
48. Zweegman S, van der Holt B, Mellqvist UH, et al. Melphalan, prednisone, and lenalidomide versus melphalan, prednisone, and thalidomide in untreated multiple myeloma. Blood 2016;127:1109-1116.

49. Facon T, Mary JY, Hulin C, et al. Melphalan and prednisone plus thalidomide versus melphalan and prednisone alone or reduced-intensity autologous stem cell transplantation in elderly patients with multiple myeloma (IFM 99-06): a randomised trial. Lancet 2007;370:12091218.

50. Hulin C, Facon T, Rodon P, et al. Efficacy of melphalan and prednisone plus thalidomide in patients older than 75 years with newly diagnosed multiple myeloma: IFM o1/o1 trial. J Clin Oncol 2009;27:3664-3670.

51. Beksac M, Haznedar R, Firatli-Tuglular T, et al. Addition of thalidomide to oral melphalan/prednisone in patients with multiple myeloma not eligible for transplantation: results of a randomized trial from the Turkish Myeloma Study Group. Eur J Haematol 2011;86:16-22.

52. Kagoya Y, Nannya Y, Kurokawa M. Thalidomide maintenance therapy for patients with multiple myeloma: meta-analysis. Leuk Res 2012;36:1016-1021.

53. Moreau P, Pylypenko H, Grosicki S, et al. Subcutaneous versus intravenous administration of bortezomib in patients with relapsed multiple myeloma: a randomised, phase 3, non-inferiority study. Lancet Oncol 2011;12:431440.

54. Palumbo A, Bringhen S, Kumar SK, et al. Second primary malignancies with lenalidomide therapy for newly diagnosed myeloma: a meta-analysis of individual patient data. Lancet Oncol 2014;15:333-342.

55. Paiva B, Vidriales MB, Cervero J, et al. Multiparameter flow cytometric remission is the most relevant prognostic factor for multiple myeloma patients who undergo autologous stem cell transplantation. Blood 2008;112:40174023 .

56. Chng WJ, Dispenzieri A, Chim CS, et al. IMWG consensus on risk stratification in multiple myeloma. Leukemia 2014;28:269-277.

57. Paiva B, Gutierrez NC, Rosinol L, et al. High-risk cytogenetics and persistent minimal residual disease by multiparameter flow cytometry predict unsustained complete response after autologous stem cell transplantation in multiple myeloma. Blood 2012;119:687-691. 